\title{
Wind Turbines Controllers Design Based on the Super-Twisting Algorithm*
}

\author{
Y. Vidal ${ }^{1}$, L. Acho ${ }^{1}$, J. Rodellar ${ }^{1}$ and C. Tutivén ${ }^{1}$
}

\begin{abstract}
The continuous increase in the size of wind turbines (WTs) has led to new challenges in the design of novel torque and pitch controllers. Today's WT control design must fulfill numerous specifications to assure effective electrical energy production and to hold the tower vibrations inside acceptable levels of operation. Hence, this paper presents modern torque and pitch control developments based on the super-twisting algorithm (STA) by using feedback of the foreaft and side-to-side acceleration signals of the WT tower. According to numerical experiments realized using FAST, these controllers mitigate vibrations in the tower without affecting the quality of electrical power production. Moreover, the proposed controllers' performance is better than the baseline controllers used for comparison.
\end{abstract}

\section{INTRODUCTION}

The further growth of the wind energy industry depends mainly on the technological developments, especially considering production and construction methods of the turbines [1], [2]. From the certification authorities, the specified minimum design lifetime of a new wind turbine (WT) is only 20 years (see, for example, [3]). This lifetime is short in economical terms when considering production and maintenance costs. The performance of a WT is primarily determined by its tower height and rotor diameter (see, for instance, [3]). Onshore WTs towers carry, besides static gravity loading from nacelle, wind induced loadings from the rotor. These dynamic loadings threaten structural safety and affect the lifetime of the WTs. Several methods can be applied to mitigate the tower vibrations and achieve a better structural response. Mostly used methods can be classified as blade pitch control (see, for example, [4]) and tuned mass dampers (see [5], and [6]). Most of the modern WTs use blade pitch control and brake systems, which regulate automatically the angle and speed of rotor blades depending on the wind speed and operational conditions. By means of these measures, the WTs can regulate power and avoid critical high rotor speeds. These methods to mitigate vibrations are especially effective at high wind speeds (full load region) inducing transient tower vibrations. This work proposes new torque and pitch controllers based on the super-twisting algorithm (STA) that, without affecting the electric power production, mitigate

\footnotetext{
*This work has been partially funded by the Spanish Ministry of Economy and Competitiveness through the research project DPI2014-58427-C2$1-\mathrm{R}$, and by the Catalonia Government through the research project 2014 SGR 859.

1 Barcelona College of Industrial Engineering, Control Dynamics and Applications Research Group (CoDAlab), Universitat Politècnica de Catalunya, 08036 Barcelona, Spain \{yolanda.vidal, leonardo.acho, jose.rodellar, christian.tutiven\}@upc.edu
}

vibrations in the tower when working in the above rated zone (full load region). The FAST simulation software is used to compare the performance of the proposed controllers with respect to the baseline controllers in the literature.

In previous works (see [7], [8], and [9]), it has been proposed the use of classical Sliding Mode Control (SMC) for WT control. Such approaches deal efficiently with the power regulation objective and provide the advantage of robustness against system uncertainties and perturbations, such as measurement noise. Although classical SMC has shown good performance in an uncountable number of applications, its well-known drawback has been the discontinuous behavior of the computed control inputs that may derive into a high-frequency oscillation known as chattering (see [10]). Among great variety of chattering suppression methods, socalled high-order sliding mode control has been studied intensively within the last decade (see, for example, [11]) and has been applied in a wide variety of fields (see, for instance, [12], [13], [14], and [15]). The twisting and supertwisting control algorithms are intended for designing the second-order sliding mode. Both of them imply an additional integrator in the system input, and the second-order sliding mode appears after a finite time interval without the firstorder sliding mode in the reaching stage (see [16]). While the twisting algorithm needs an additional differentiator (preserving the structural requirement for the common firstorder sliding mode), the super-twisting algorithm (STA) does not need it. The remarkable properties of the STA are: a) accurately regulating and tracking accomplished with finitetime convergence; b) as the control input is a continuous state function, there is a reduction of mechanical stresses (see [17]) and chattering; c) time derivative of the output is not needed; d) robustness with respect to various internal and external disturbances and model uncertainties; e) relatively simple control laws that can be designed based on nonlinear models. These properties explain high level of research activity related to stability analysis, estimation of the convergence time, and estimation of the admissible range of disturbances (see, among others, [18], [11], [19], and [20]). It is noteworthy the work of [17] where STA is used to control WT operating in the partial load zone (thus the control objective is to extract the maximum power from the wind). In this work we focus in the full load region (the control objective is to regulate the electrical power) where, not only torque control, but also pitch control is required, and an extra control attribute is imposed: vibration mitigation.

The work is divided into four main sections, where the first one is this introduction. The second section presents 
general control concepts for WTs and the selected 5 MW WT used to design the proposed controllers. Also, for comparison purposes, a well-known baseline control strategy for the 5 MW WT is recalled in this section. The third section shows the process to design the proposed robust controllers. These controllers are based on the super-twisting method and their control actions are for the above rated power production control zone. The fourth section analyzes simulation results in FAST using the proposed controllers and compared to the baseline control strategy. The last section summarizes the conclusions of this work.

\section{WIND TURBINE DESCRIPTION}

A complete description of the wind turbine model can be found in [21]. Hereafter, only the generator-converter actuator model, the pitch actuator model and the baseline control strategy are recalled in order to introduce the notation and the concepts employed in following sections. In the appendix, a table is given with the gross properties of the WT II.

\section{A. Generator-Converter Model}

The generator-converter system can be approximated by a first-order differential equation, see [22], which is given by:

$$
\dot{\tau_{r}}(t)+\alpha_{g c} \tau_{r}(t)=\alpha_{g c} \tau_{c}(t)
$$

where $\tau_{r}$ and $\tau_{c}$ are the real generator torque and its reference (given by the controller), respectively. In the numerical simulations, $\alpha_{g c}=50$, see [23]. Moreover, the power produced by the generator, $P_{e}(t)$, can be expressed as (see [22]):

$$
P_{e}(t)=\eta_{g} \omega_{g}(t) \tau_{r}(t)
$$

where $\eta_{g}$ is the efficiency of the generator and $\omega_{g}$ is the generator speed. In the numerical experiments, $\eta_{g}=0.98$ is used, as in [22].

\section{B. Pitch Actuator Model}

The pitch actuator can be modeled as a second-order linear differential equation with time-dependent variables, pitch angle $\beta(t)$ and its reference $\beta_{c}(t)$ (given by the controller), [22]:

$$
\ddot{\beta}(t)+2 \xi \omega_{n} \dot{\beta}(t)+\omega_{n}^{2} \beta(t)=\omega_{n}^{2} \beta_{c}(t),
$$

where $\omega_{n}$ and $\xi$ are the natural frequency and the damping ratio, respectively. In the numerical experiments, $\xi=0.6$ and $\omega_{n}=11.11 \mathrm{rad} / \mathrm{s}$ are utilized, see [22].

\section{Baseline Torque and Pitch Controllers}

The baseline torque and pitch controllers specifications are described in the technical report [23] by the U.S. Department of Energy's National Renewable Energy Laboratory (NREL). Here a brief review of these controllers is given as its performance will be used for comparison with the proposed techniques.

In the full load region of operation, the torque controller objective is to maintain constant the generated power; thus,

$$
\tau_{c}(t)=\frac{P_{\text {ref }}}{\hat{\omega}_{g}(t)},
$$

where $P_{\text {ref }}$ is the reference power and $\hat{\omega}_{g}$ is the filtered generator speed (see [23]). As the generator may not be able to supply the desired torque depending on the operating conditions, the torque controller is saturated to a maximum of $47,402.9 \mathrm{Nm}$ and a maximum rate limit of $15,000 \mathrm{Nm} / \mathrm{s}$; see [23].

When working in the full load region, a pitch controller is needed to assist the torque controller and regulate the generator speed. The collective blade pitch gain scheduling PI-controller (GSPI) is one of the first well-documented controllers, and it is used in the literature as a baseline controller to compare the obtained results. This controller was originally developed by Jonkman for the standard landbased 5-MW turbine [23]. The GSPI control has the filtered generator speed, $\hat{\omega}_{g}(t)$, as the input and the pitch servo setpoint, $\beta_{r}(t)$, as the output. That is,

$$
\begin{gathered}
\beta_{r}(t)=K_{p}(\theta)\left(\hat{\omega}_{g}(t)-\omega_{g n}\right)+K_{i}(\theta) \int_{0}^{t}\left(\hat{\omega}_{g}(\tau)-\omega_{g n}\right) d \tau, \\
K_{p}>0, K_{i}>0
\end{gathered}
$$

where $\omega_{g n}$ is the nominal generator speed (at which the rated electrical power of the WT is obtained) and the scheduling parameter $\theta$ is taken to be the previously measured collective blade pitch angle. The pitch angle actuators generally present hard constraints on their amplitude and their speed response. Because of this, a pitch limit saturation to a maximum of $45^{\circ}$ and a pitch rate saturation of $8^{\circ} / \mathrm{s}$ are implemented (see [23]) to avoid, for instance, pitch actuator damage.

\section{PROBLEM STATEMENT}

It is not the purpose of this work to review the supertwisting algorithm (STA). A comprehensive analysis is conducted, for instance, in [11]. Here, the scalar STA (see [24]) is recalled and used to design new torque and pitch controllers. In spite of the coupling existing in WTs, most control strategies for WT uncouple the control problem into different Single Input Single Ouput (SISO) control loops to make easier the control system design (see, for example, [4]). In this work the uncoupled control scheme viewpoint is used where:

- Torque control objectives are to regulate the electrical power and mitigate loads in the side-to-side direction.

- Pitch control objectives are to regulate the generator speed and mitigate loads in the fore-aft direction.

Note that both controllers, in the closed-loop system, work together to obtain an electrical power regulated to the rated electrical power and, at the same time, a generator speed regulated to its nominal value. Obviously, the ideal torque control magnitude will be close to the nominal torque value, $\tau_{c n}$, given by

$$
\tau_{c n}=P_{\text {ref }} / \omega_{g n}
$$

\section{A. Controllers Design}

On one hand, we propose the scalar STA-based torque controller

$$
\tau_{c}(t)=-\alpha_{1} \sqrt{\left|P_{e}(t)-P_{\text {ref }}\right|} \operatorname{sign}\left(P_{e}(t)-P_{\text {ref }}\right)+y(t),
$$




$$
\dot{y}(t)=-\alpha_{2} \operatorname{sign}\left(P_{e}(t)-P_{\text {ref }}\right)+\alpha_{3} a_{s s}(t),
$$

where $\alpha_{1}, \alpha_{2}, \alpha_{3}>0$ and $a_{s s}(t)$ is the side-to-side acceleration measured at the tower top. Note that we introduce the acceleration as a feedback signal to give the controller the ability to face with vibrations. A stability analysis for this controller is given in the next subsection.

On the other hand, we propose to modify the baseline gain-scheduling pitch controller in the form

$$
\begin{gathered}
\beta_{c}(t)=K_{p}(\theta)\left(\hat{\omega}_{g}(t)-\omega_{g n}\right)+K_{i}(\theta) z(t), \\
\dot{z}(t)=\operatorname{sign}\left(\hat{\omega}_{g}(t)-\omega_{g n}\right)+\alpha_{4} a_{f a}(t),
\end{gathered}
$$

where $\alpha_{4}>0$ and $a_{f a}(t)$ is the fore-aft acceleration measured at the tower top. Note that the acceleration is introduced, similarly to the torque controller, as a feedback signal. For the proposed pitch controller, as it is a gainscheduling proportional integral control, the controller gains have been heuristically tuned following the same procedure as in [23].

The block diagram in Figure 1 shows the connections between the WT, and the proposed torque and pitch controllers.

\section{B. Torque Control Stability Analysis}

For a perfectly rigid low-speed shaft, a single-mass model for a wind turbine can be considered ([25], [26], [27], [28]),

$$
J_{t} \dot{\omega}_{g}(t)=T_{a}(t)-\tau_{c}(t),
$$

where $J_{t}$ is the turbine total inertia $\left(\mathrm{Kg} \mathrm{m} \mathrm{m}^{2}\right), \tau_{c}$ is the generator torque $(\mathrm{Nm})$, and $T_{a}$ is the aerodynamic torque $(\mathrm{Nm})$ described as

$$
T_{a}(t)=\frac{1}{2} \rho \pi R^{2} \frac{C_{p}(\lambda, \beta)}{\omega_{r}(t)} u^{3}(t)
$$

where $\rho$ is the air density $\left(\mathrm{kg} / \mathrm{m}^{3}\right), R$ is the rotor radius $(\mathrm{m}), \omega_{r}(t)$ is the rotor speed $(\mathrm{rad} / \mathrm{s}), u(t)$ is the wind speed $(\mathrm{m} / \mathrm{s})$, and $C_{p}(\lambda, \beta)$ is the power coefficient (bounded by the Betz limit). Note that, due to physical constraints, the aerodynamic torque is bounded. Thus, it is realistic to assume that $0<T_{a}(t) \leq \gamma, \forall t \geq 0$.

The STA-based torque control objective is to regulate the electrical power. That is, we define the error:

$$
e(t)=P_{e}(t)-P_{\text {ref }}
$$

The control objective is that it converges to zero as time goes on. It is obvious that

$$
\dot{e}(t)=\dot{P}_{e}(t)=\eta_{g}\left[\dot{\omega}_{g}(t) \tau_{r}(t)+\omega_{g}(t) \dot{\tau}_{r}(t)\right] .
$$

Using equations 1 and 7, from the generator-converter model and WT model respectively, the error dynamics can be written as

$\dot{e}(t)=\eta_{g}\left[J_{t}^{-1}\left(T_{a}-\tau_{c}(t)\right) \tau_{r}(t)+\alpha_{g c} \omega_{g}(t)\left(\tau_{c}(t)-\tau_{r}(t)\right)\right]$

and, assuming that $\tau_{c}(t)-\tau_{r}(t) \approx 0$, it can be simplified to

$$
\dot{e}(t)=\eta_{g} J_{t}^{-1} T_{a}(t) \tau_{c}(t)-\eta_{g} J_{t}^{-1} \tau_{c}^{2}(t) .
$$

Finally, linearizing the previous dynamic around $\tau_{c}(t)=0$, the error dynamics becomes

$$
\dot{e}(t)=\eta_{g} J_{t}^{-1} T_{a}(t) \tau_{c}(t),
$$

and, as $\eta_{g} J_{t}^{-1} T_{a}(t)$ is positive and bounded, to prove the local stability of this system is equivalent to study the local stability conditions of the system

$$
\dot{e}(t)=\tau_{c}(t) .
$$

This system, after substituting in equation 5 , gives the closedloop error dynamics:

$$
\begin{aligned}
& \dot{e}(t)=-\alpha_{1} \sqrt{|e|} \operatorname{sign}(e)+y, \\
& \dot{y}=-\alpha_{2} \operatorname{sign}(e)+\alpha_{3} a_{s s}(t) .
\end{aligned}
$$

Since we consider that the side-to-side acceleration, $a_{s s}(t)$, is a bounded signal (giving the controller the ability to face with vibrations), system $9-10$ is stable as has been proven in [20]. This finally concludes the stability of the proposed torque control.

\section{SIMULATION RESULTS}

The wind turbine simulator software FAST is used for the numerical experiments to assess the effectiveness of the proposed strategy. The results compare the performance of the contributed super-twisting controllers with respect to the previously described baseline controllers.

The response of the electrical power and accelerations at the tower top are analyzed in terms of the integral absolute error through the following performance indices:

$$
\begin{gathered}
J_{1}(t)=\int_{0}^{t}\left|a_{f a}(\tau)\right| d \tau,[\mathrm{m} / \mathrm{s}] \\
J_{2}(t)=\int_{0}^{t}\left|a_{s s}(\tau)\right| d \tau,[\mathrm{m} / \mathrm{s}] \\
J_{3}=\max _{0 \leq t \leq T_{f}}\left|a_{f a}(t)\right|,\left[\mathrm{m} / \mathrm{s}^{2}\right] \\
J_{4}=\max _{0 \leq t \leq T_{f}}\left|a_{s s}(t)\right|,\left[\mathrm{m} / \mathrm{s}^{2}\right] \\
J_{P}(t)=\int_{0}^{t}\left|P_{e}(\tau)-P_{\mathrm{ref}}\right| d \tau,[J]
\end{gathered}
$$

where $T_{f}$ is the final simulation time, and recall that $a_{f a}(t)$ and $a_{s s}(t)$ are the fore-aft and the side-to-side accelerations, respectively, at the tower top.

According to the numerical results, the proposed controllers improve the power generation quality as can be seen in Figure 2. Due to the rate-limiter action and the complexity of the WT model used for simulation (FAST), the finitetime convergence behavior of the STA torque controller is not evidenced in the results, as can be seen in Figure 2 (top). This is because of the discrete time realization of the controllers (fixed integration time-step of $0.0125 \mathrm{~s}$ ). The $J_{P}$ index is improved, that is the error in the regulation of the electrical power is reduced. In a 600 seconds simulation, the accumulated error is halved with respect to the baseline strategy as can be seen in Figure 2 (bottom). 


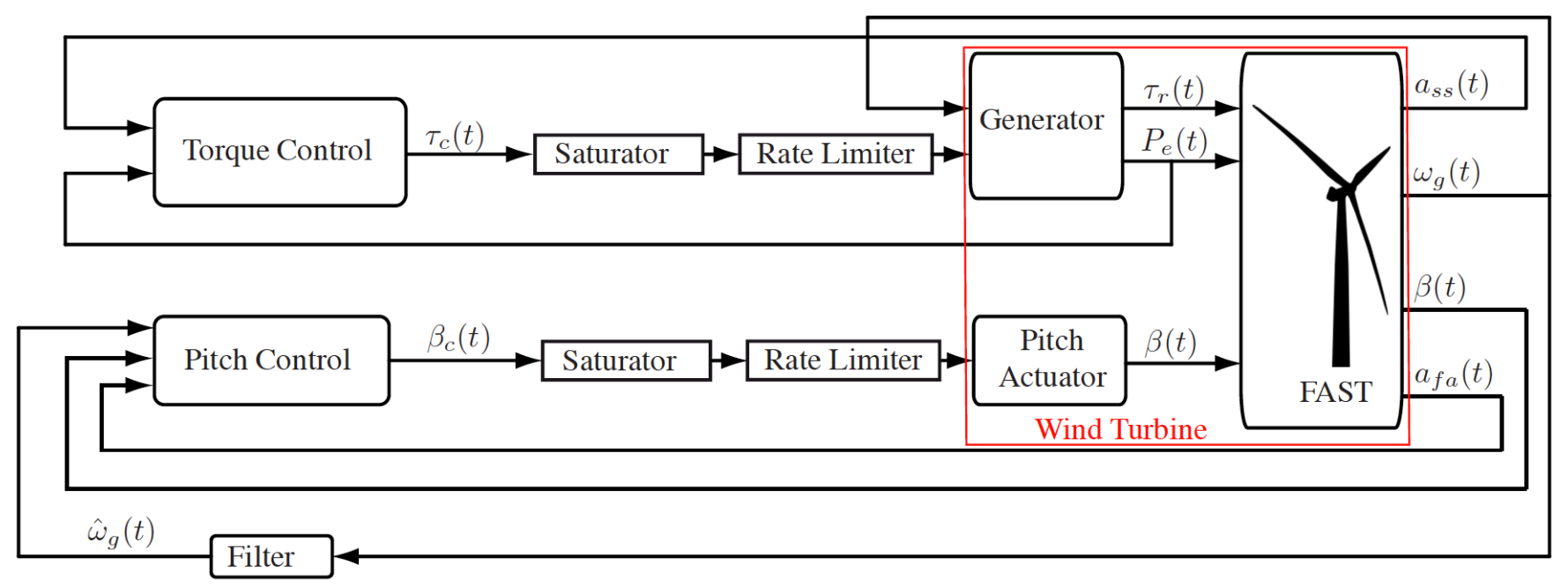

Fig. 1. Block diagram of the closed-loop system.

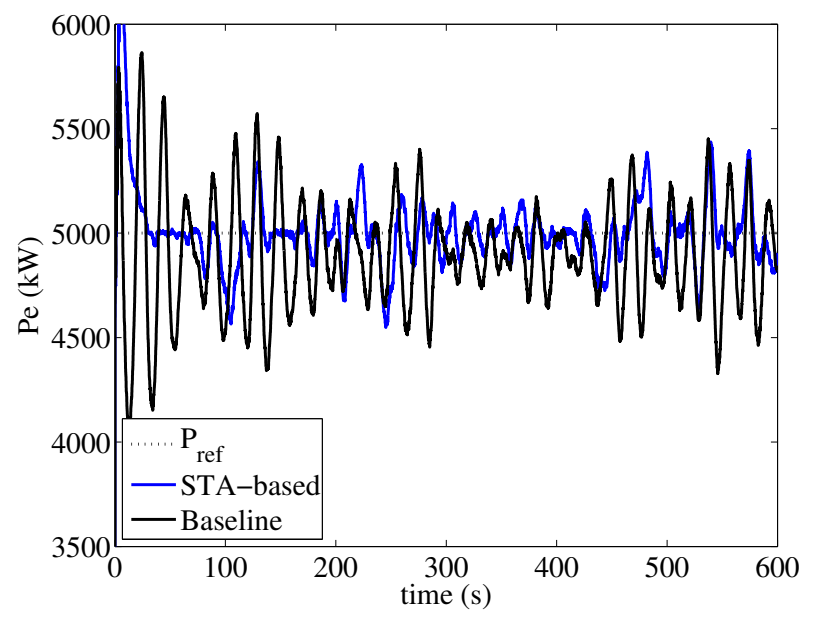

torque generator remains smooth and tracks more efficiently the wind fluctuations than in standard control. Indeed, and as expected, this leads to a reduction of the accelerations in the tower, as can be seen in Figures 4 and 5. Table I shows
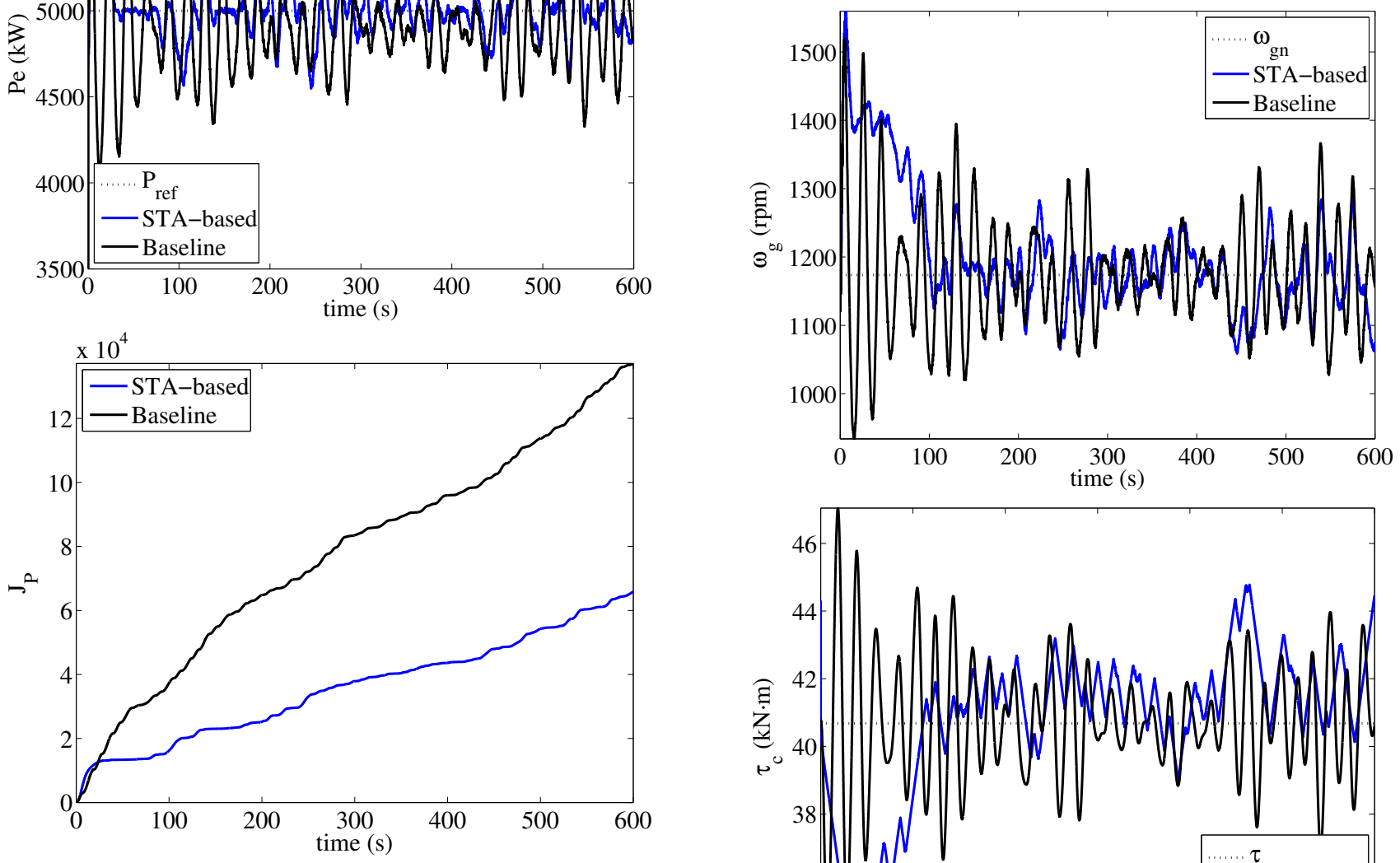

Fig. 2. Electrical power (top) and $J_{P}$ index (bottom).

The generator speed, $\omega_{g}$, is very smooth with no chattering as shown in Figure 3 (top). The proposed STA does not induce increased mechanical stress as there are no strong torque variations, as can be seen in Figure 3 (bottom). The

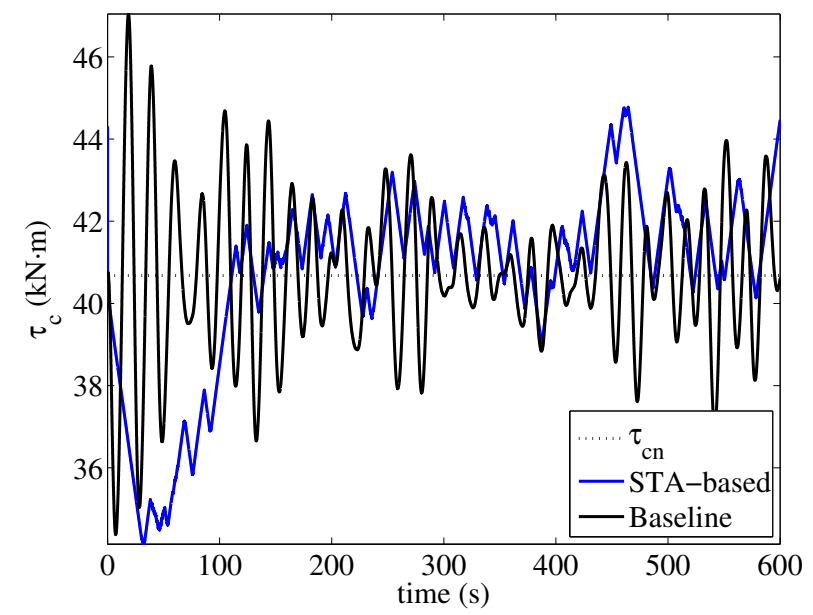

Fig. 3. Generator speed (top) and torque control (bottom).

that, using the the STA-based controllers, the accelerations 

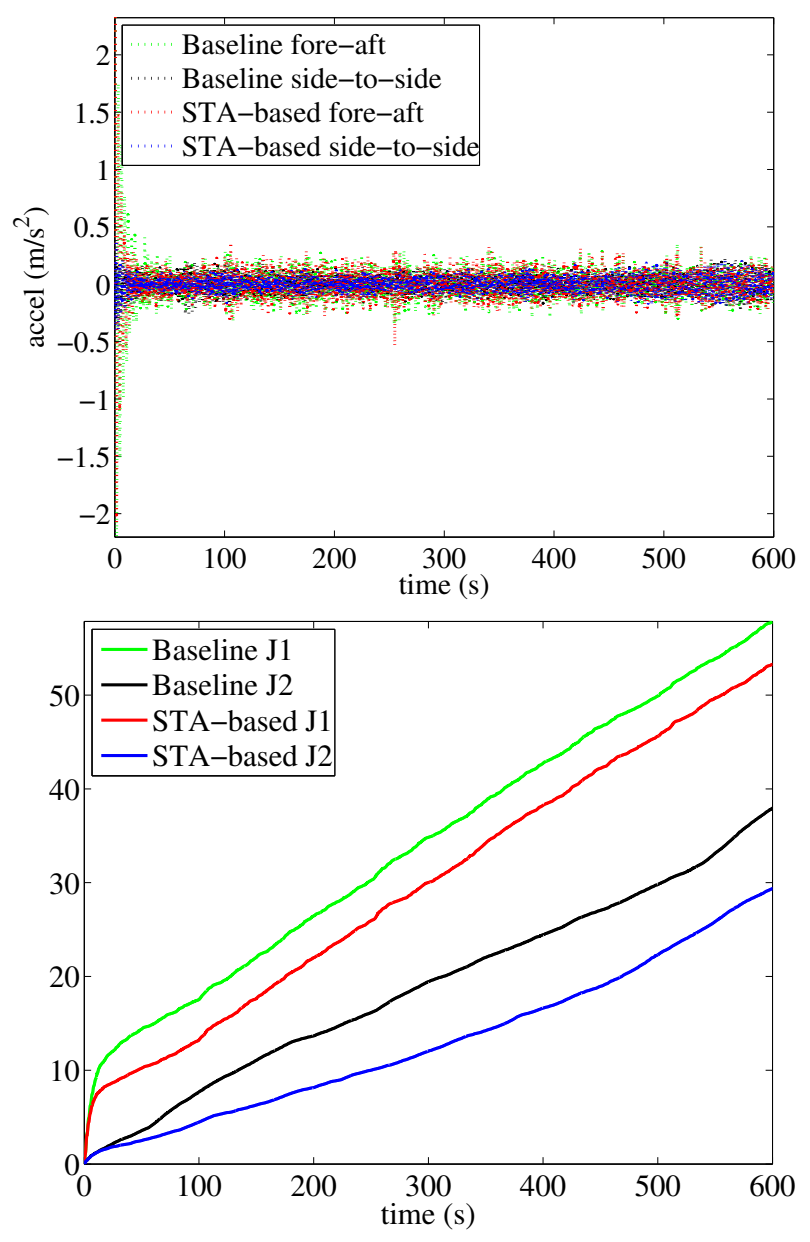

Fig. 4. Fore-aft and side-to-side accelerations (top) and related indices (bottom) at the tower top.

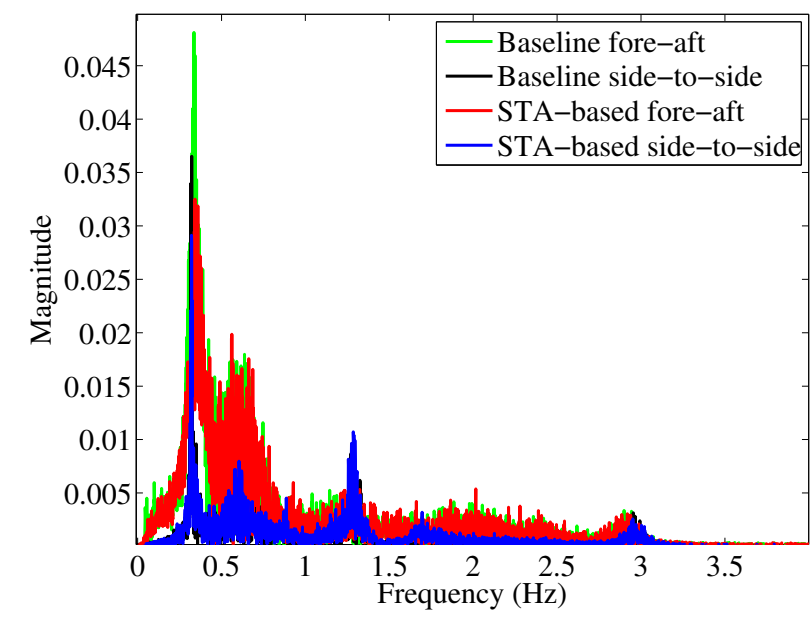

Fig. 5. Frequency spectra of the fore-aft and side-to-side accelerations at the tower top.

in the fore-aft direction (index $J_{1}$ ) have been improved as well as accelerations in the side-to-side direction (index $J_{2}$ ). Maximum absolute values of the accelerations (indices $J_{3}$ and $\left.J_{4}\right)$ are the same for the baseline and STA-based controllers. Finally, note that the performance power index, $J_{P}$, has also been improved (is halved with respect to the baseline strategy).

TABLE I

NUMERICAL RESULTS: PERFORMANCE INDICES.

\begin{tabular}{llllll}
\hline & $J_{1}\left(T_{f}\right)$ & $J_{2}\left(T_{f}\right)$ & $J_{3}$ & $J_{4}$ & $J_{P}\left(T_{f}\right)$ \\
\hline Baseline & 57.85 & 37.95 & 2.32 & 0.40 & $1.37 \times 10^{5}$ \\
STA-based & 53.28 & 29.37 & 2.32 & 0.40 & $6.57 \times 10^{4}$ \\
\hline
\end{tabular}

Recall that, when designing the pitch angle control loop, it is of great importance to avoid a high activity of the pitch, since it could not only damage the pitch actuators but also give rise to unstable modes of operation, see, for instance, [29]. The pitch control, shown in Figure 6, is smoothed with the STA-based controllers. This lower pitch activity leads to lower mechanical stress (vibration mitigation) spreading the wind turbine lifetime and also resulting in softer output power.

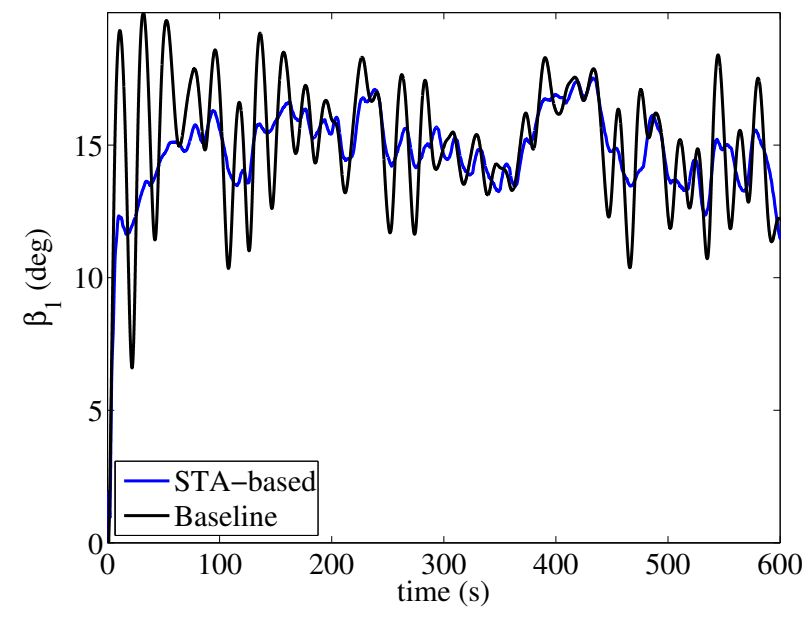

Fig. 6. Pitch angle.

Figure 7 shows the displacements at the tower top. Comparison of the proposed method with the baseline concludes, as expected, that displacements are diminished.

Remark. The gains $\alpha_{1}=0.1, \alpha_{2}=200, \alpha_{3}=1$, and $\alpha_{4}=5$ are used in the simulations. They are selected in order to reduce the fore-aft motion, since this mode has been identified as the main fatigue driver, see [30].

\section{CONCLUSIONS}

Tower vibrations threaten the structural stability and reduce the lifetime of wind turbines significantly. This work contributes new torque and pitch controllers that reduce the fore-aft and side-to-side accelerations with respect to the baseline control. The effectiveness to mitigate tower vibrations of the proposed STA-based torque and pitch controllers is evidenced. Even more, they present other attractive features such as robustness to parametric uncertainties of the turbine and the generator as well as to electric grid disturbances. 


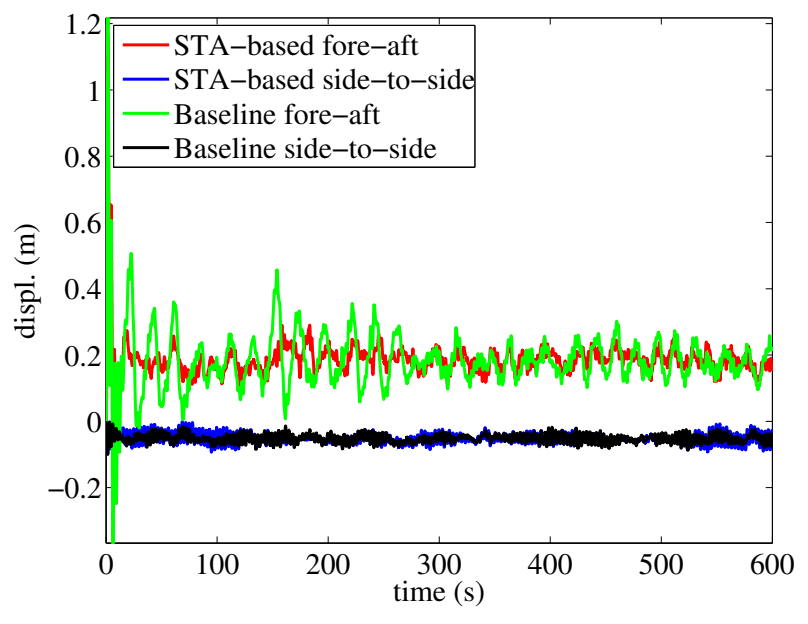

Fig. 7. Fore-aft and side-to-side displacements at the tower top.

\section{APPENDIX}

TABLE II

GROSS PROPERTIES OF THE WIND TURBINE [23].

\begin{tabular}{ll}
\hline Reference wind turbine & \\
\hline Rated power & $5 \mathrm{MW}$ \\
Number of blades & 3 \\
Rotor/Hub diameter & $126 \mathrm{~m}, 3 \mathrm{~m}$ \\
Hub Height & $90 \mathrm{~m}$ \\
Cut-In, Rated, Cut-Out Wind Speed & $3 \mathrm{~m} / \mathrm{s}, 11.4 \mathrm{~m} / \mathrm{s}, 25 \mathrm{~m} / \mathrm{s}$ \\
Rated generator speed $\left(\omega_{g n}\right)$ & $1173.7 \mathrm{rpm}$ \\
Rated generator torque $\left(\tau_{c n}\right)$ & $40683 \mathrm{Nm}$ \\
Gearbox ratio & 97 \\
\hline
\end{tabular}

\section{REFERENCES}

[1] P. F. Odgaard, J. Stoustrup, and M. Kinnaert, "Fault-tolerant control of wind turbines: A benchmark model," Control Systems Technology, IEEE Transactions on, vol. 21, no. 4, pp. 1168-1182, 2013.

[2] M. S. Shaker and R. J. Patton, "Active sensor fault tolerant output feedback tracking control for wind turbine systems via t-s model," Engineering Applications of Artificial Intelligence, vol. 34, pp. 1-12, 2014.

[3] O. Altay, F. Taddei, C. Butenweg, and S. Klinkel, "Vibration mitigation of wind turbine towers with tuned mass dampers," in Wind Turbine Control and Monitoring, ser. Advances in Industrial Control, N. Luo, Y. Vidal, and L. Acho, Eds. Springer International Publishing, 2014, pp. 337-373.

[4] A. Diaz de Corcuera, A. Pujana-Arrese, J. M. Ezquerra, A. Milo, and J. Landaluze, "Design of robust controllers for load reduction in wind turbines," in Wind Turbine Control and Monitoring, ser. Advances in Industrial Control, N. Luo, Y. Vidal, and L. Acho, Eds. Springer International Publishing, 2014, pp. 97-133.

[5] N. Caterino, C. Georgakis, F. Trinchillo, and A. Occhiuzzi, "A semiactive control system for wind turbines," in Wind Turbine Control and Monitoring, ser. Advances in Industrial Control, N. Luo, Y. Vidal, and L. Acho, Eds. Springer International Publishing, 2014, pp. 375-407.

[6] H. R. Karimi, M. Zapateiro, and N. Luo, "Semiactive vibration control of offshore wind turbine towers with tuned liquid column dampers using h $\infty$ output feedback control," in Control applications (CCA), 2010 IEEE international conference on. IEEE, 2010, pp. 2245-2249.

[7] Y. Vidal, L. Acho, N. Luo, M. Zapateiro, and F. Pozo, "Power Control Design for Variable-Speed Wind Turbines," Energies, vol. 5, no. 8, pp. 3033-3050, AUG 2012.

[8] O. Barambones, "Sliding mode control strategy for wind turbine power maximization," Energies, vol. 5, no. 7, pp. 2310-2330, 2012.
[9] B. Beltran, T. Ahmed-Ali, and M. E. H. Benbouzid, "Sliding mode power control of variable-speed wind energy conversion systems," Energy Conversion, IEEE Transactions on, vol. 23, no. 2, pp. 551-558, 2008.

[10] V. Utkin, J. Guldner, and J. Shi, Sliding mode control in electromechanical systems. CRC press, 2009, vol. 34.

[11] V. Utkin, "On convergence time and disturbance rejection of supertwisting control," Automatic Control, IEEE Transactions on, vol. 58, no. $8,2013$.

[12] S. Janardhanan, P. Tiwari, et al., "Attitude control of magnetic actuated spacecraft using super-twisting algorithm with nonlinear sliding surface," in Variable Structure Systems (VSS), 2012 12th International Workshop on. IEEE, 2012, pp. 46-51.

[13] M. Lopez-Franco, A. Salome-Baylon, A. Y. Alanis, and N. AranaDaniel, "Discrete super twisting control algorithm for the nonholonomic mobile robots tracking problem," in Electrical Engineering Computing Science and Automatic Control (CCE), 2011 8th International Conference on. IEEE, 2011, pp. 1-5.

[14] L. Derafa, L. Fridman, A. Benallegue, and A. Ouldali, "Super twisting control algorithm for the four rotors helicopter attitude tracking problem," in Variable Structure Systems (VSS), 2010 11th International Workshop on. IEEE, 2010, pp. 62-67.

[15] S. Kuntanapreeda, "Super-twisting sliding-mode traction control of vehicles with tractive force observer," Control Engineering Practice, vol. 38, pp. 26-36, 2015.

[16] A. Levant, "Sliding order and sliding accuracy in sliding mode control," International journal of control, vol. 58, no. 6, pp. 1247$1263,1993$.

[17] C. Evangelista, P. Puleston, F. Valenciaga, and A. Dávila, "Variable gains super-twisting control for wind energy conversion optimization," in Variable Structure Systems (VSS), 2010 11th International Workshop on. IEEE, 2010, pp. 50-55.

[18] V. Utkin, "About second order sliding mode control, relative degree, finite-time convergence and disturbance rejection," in Variable Structure Systems (VSS), 2010 11th International Workshop on. IEEE, 2010, pp. 528-533.

[19] M. Basin and P. Rodriguez-Ramirez, "A super-twisting control algorithm for systems of relative degree more than one," in Control Conference (ASCC), 2013 9th Asian. IEEE, 2013, pp. 1-6.

[20] J. A. Moreno, "On strict lyapunov functions for some nonhomogeneous super-twisting algorithms," Journal of the Franklin Institute, vol. 351, no. 4, pp. 1902-1919, 2014.

[21] Y. Vidal, C. Tutiven, J. Rodellar, and L. Acho, "Fault diagnosis and fault-tolerant control of wind turbines via a discrete time controller with a disturbance compensator," Energies, vol. 8, no. 5, p. 4300, 2015.

[22] P. Odgaard and K. Johnson, "Wind turbine fault diagnosis and fault tolerant control - an enhanced benchmark challenge," in Proc. of the 2013 American Control Conference-ACC,(Washington DC, USA), 2013, pp. 1-6.

[23] J. M. Jonkman, S. Butterfield, W. Musial, and G. Scott, "Definition of a 5-MW reference wind turbine for offshore system development," National Renewable Energy Laboratory, Golden, Colorado, Tech. Rep., 2009, nREL/TP-500-38060.

[24] A. Levant, "Robust exact differentiation via sliding mode technique,' Automatica, vol. 34, no. 3, pp. 379-384, 1998.

[25] B. Boukhezzar, L. Lupu, H. Siguerdidjane, and M. Hand, "Multivariable control strategy for variable speed, variable pitch wind turbines," Renewable Energy, vol. 32, no. 8, pp. 1273 - 1287, 2007.

[26] N. Khezami, N. B. Braiek, and X. Guillaud, "Wind turbine power tracking using an improved multimodel quadratic approach," ISA Transactions, vol. 49, no. 3, pp. 326 - 334, 2010.

[27] L. Acho, Y. Vidal, and F. Pozo, "Robust variable speed control of a wind turbine," International Journal of Innovative Computing, Information and Control, vol. 6, no. 4, pp. 1925 -1933, 2010.

[28] B. Beltran, T. Ahmed-Ali, and M. Benbouzid, "High-order slidingmode control of variable-speed wind turbines," Industrial Electronics, IEEE Transactions on, vol. 56, no. 9, pp. 3314 -3321, sept. 2009.

[29] F. D. Bianchi, H. De Battista, and R. J. Mantz, Wind turbine control systems: principles, modelling and gain scheduling design. Springer Science \& Business Media, 2006.

[30] W. Leithead and S. Dominguez, "Controller design for the cancellation of the tower fore-aft mode in a wind turbine," in Decision and Control, 2005 and 2005 European Control Conference. CDC-ECC'05. 44th IEEE Conference on. IEEE, 2005, pp. 1276-1281. 